\title{
Characteristics of internal-wave and internal-tide deposits and their hydrocarbon potential
}

\author{
He Youbin*, Gao Zhenzhong, Luo Jinxiong, Luo Shunshe and Liu Xuefeng
}

School of Geosciences, Yangtze University, Jingzhou, Hubei 434023, China

\begin{abstract}
The study of internal-wave and internal-tide deposits is a new research field on sedimentology during the last ten years. Deep-water traction currents induced by internal waves and internal tides are developed on the modern sea floor, which can form not only all kinds of small scale and dispersal deepwater traction currents deposits, but also large-scale sediment wave in km-size scale. In this paper, the concepts and features of internal waves and internal tides in oceanography are introduced, and the characteristics, sedimentary sequences, sedimentary microfacies and sedimentation models of internalwave and internal-tide deposits found and the origin of large scale sediment waves in deep sea bottom are summarized. The relationship between internal-wave and internal-tide deposits and petroleum is discussed, and finally internal-wave and internal-tide deposits are shown to be a new potential field for petroleum exploration.
\end{abstract}

Key words: Internal wave, internal-tide deposits, sediment wave, hydrocarbon potential

The successful Deep Sea Drilling Program (DSDP) and Ocean Drilling Program (ODP) revealed that there were large-scale clastic deposits formed by deep-water traction currents in the abyssal and bathyal environment. The deepwater traction current deposits discovered so far include contour-current deposits and internal-wave and internal-tide deposits. Petroleum exploration has demonstrated that the deep-water gravity flow deposits contain abundant oil and gas resources. The deep-water traction current deposits have similar conditions of source-reservoir-cap rock to the gravity flow deposits, so the reservoirs formed by the deep-water traction current deposits must be a new frontier for oil and gas exploration. However, in the field of petroleum geology, such reservoirs have not yet been systematically studied. This paper only discusses the characteristics and potential of internal-wave and internal-tide deposits.

\section{Concepts of internal waves and internal tides}

Internal waves are subsurface waves that develop either between water layers of different densities or within layers where vertical density gradients are present (LaFond, 1966), and it is a kind of wave in the interior of oceans that exists between water layers with different densities (Yang, 1994; Du et al, 2001). Munk (1981) postulated that the gravity waves in the interior of oceans are as common as waves on the ocean surface and perhaps even more so. Because the energy of internal waves is much less than the corresponding surface waves, just a small amount of energy can induce internal waves, and this is very common. So internal waves are widely

*Corresponding author. email: heyb122@163.com

Received January 25, 2007 developed in oceans, just like waves on the sea surface (Du et al, 2001; Yang, 1986), but they vary widely in wavelength, amplitude, period, speed and depth. The wavelengths of internal waves are from much less than $1 \mathrm{~m}$ to over $10 \mathrm{~km}$. The amplitudes are from a few centimeters to over $100 \mathrm{~m}$. And the period varies from less than 1 minute to several days, even dozens days.

Internal waves cannot be monitored as we observe surface waves, but they can be measured indirectly, for example measuring the changes of temperature and salinity with time (Yang, 1986). The continuous deep-sea investigations indicate that the alternating up-and down-canyon currents exist in most submarine canyons and other types of submarine valleys in continental margins (Shepard et al, 1979). These alternating currents generated by internal waves are almost continuous. Therefore, as long as their time-velocity curves (Fig. 1) are measured, internal waves in the interior of the ocean can be displayed visually.

Fig. 1 shows that the period of internal waves is almost equal to the tides on the ocean surface. In fact, this is a kind of internal wave, whose period is equal to the semidiurnal or diurnal tide. This kind of special low-frequency internal wave is called as an internal tide (Lafond, 1966). The generation of internal tide is mainly related to the surface tide, the stratified seawater and the abruptly changing terrain. Generally, in regions with large tidal range, the average period of these upand down-canyon currents approaches semidiurnal or diurnal tides where the depth exceeds $250 \mathrm{~m}$. In regions with small tidal range, bidirectional currents, whose period tends to be the surface tides period, occur only in deeper water (Shepard, 1976).

In general, the bidirectional currents generated by internal waves and internal tides are continuous, but sometimes there may be dominantly up-canyon or down-canyon currents. 

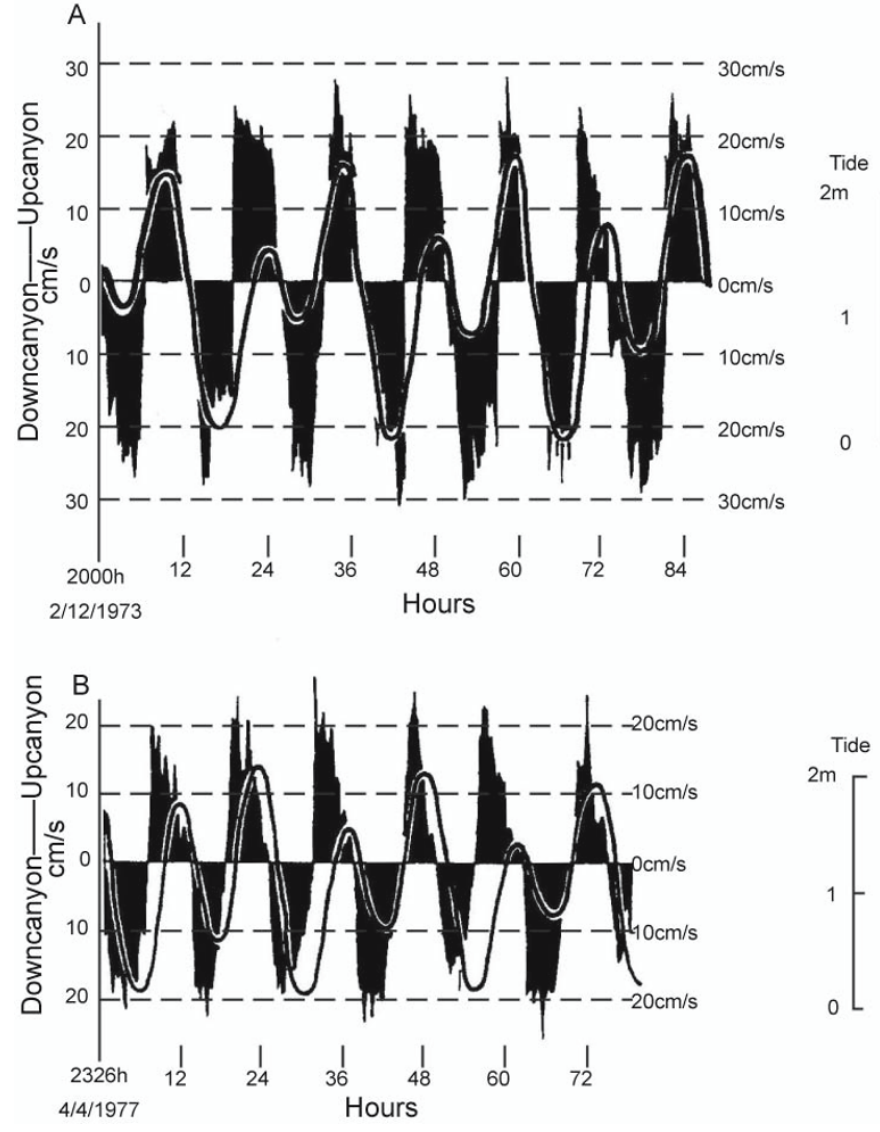

Fig. 1 Time-velocity curves of alternating up- and down-canyon currents(bars), showing a clear relationship between the current and the tide (solid curve). AStation 28 in Hueneme Canyon, depth 448 m, 3 m above bottom. B-Station 123 in San Clemente rift valley, depth 1646 m, 3 m above bottom (modified from Shepard et al, 1979)

Gao et al $(1996 ; 1998)$ suggest that when a high-energy, long-period internal wave is superimposed on a short-period internal wave or internal tide, the direction of current can be changed to some extent. So sometimes there are dominating up-canyon currents, sometimes there are dominating downcanyon currents.

Deep-sea investigations reveal that the alternating up- and down-canyon currents widely exist in submarine canyons and other types of valleys (Shepard et al, 1979). Fig. 1 display the time-velocity curves of alternating up- and down-canyon currents, which were measured in two submarine canyons off the west coast of California. The period of these currents is almost the same as the period of semidiurnal tide. They are probably generated by internal tides (Gao et al, 1996; 1998).

The speed of this kind of alternating current can reach $20-50 \mathrm{~cm} / \mathrm{s}$, which can transport sand-size sediment. Oceanfloor photography and sonar scans show the bottom shapes formed by the alternating currents, such as ripples and sand dunes (Mullins et al, 1982).

\section{Internal-tide and internal-wave deposits in the stratigraphic record}

The oceanography investigations show that internal waves and internal tides are important geological agents in deep- water areas. These geological agents have important effects on deep-water sedimentation. Therefore they must be preserved in the stratigraphic record. However, sedimentologists have not paid enough attention to this kind of geological process. Some researchers had already observed the action of internal tides in deep-water areas, for example Laird (1972) reported deep-water tidal bidirectional cross-laminations in PreDevonian in New Zealand, and Klein (1975) reported flaser, wavy and lenticular beddings in the Quaternary to Cretaceous cores from water depths of $2,200 \mathrm{~m}$ to $3,000 \mathrm{~m}$ on the Ontongjava Pleatau, but they did not carry out the research in the context of the sedimentations of internal waves and internal tides. Not until Gao Zhenzhong and K. A. Eriksson studied the Ordovician of the central Appalachians, the USA in 1990, did sedimentologists recognize internal-tide deposits in the ancient record and first use the term "internal-tide deposit" (Gao and Eriksson, 1993). Since then these sedimentary characteristics and formation mechanisms have been discussed and the sedimentary model built. So a new research field of sedimentology has been started.

The first internal-tide deposits in the stratigraphic record lies in the top of submarine canyon-filled sequence, which is composed mostly of fine sand with minor medium sand. Two microfacies were recognized: (1) "Bidirectional crosslaminated fine-sandstone microfacies", which is interpreted as the product of bidirectional currents caused by internal tides in a submarine channel. (2) "Unidirectional cross-bedded and cross-laminated fine-medium sandstone microfacies", which is interpreted as the product of an internal-tide with a superimposed long-period internal wave. (Gao and Eriksson, 1991; 1993)

Since then, Chinese sedimentologists carried out researches in this field. Internal-wave and internal-tide deposits are found in the Upper Ordovician in Tonglu, Zhejiang, the Middle and Upper Ordovician in the Tarim Basin, Xinjiang, the Lower Cambrian in Shimen, Hunan, the Devonian to Triassic in Western Qingling, Shaanxi and the Mesoproterozoic in Xiushui, Jiangxi (Gao et al, 1997; 2000; 2004; He et al, 1998; 2003; 2005; Jin et al, 2002), and these deposits have been systematically studied. Now this research has reached the phase of large-scale sediment waves (Gao et al, 2006).

However, in the last ten years, there have been a lot of research reports on internal waves and internal tides in oceanography abroad (Katsumata and Hibiya, 2002; Lerczak et al, 2003), and a paper on the sedimentation of internal waves in the modern ocean (Karl et al, 1986). But so far there has been no paper on internal-wave and internal-tide deposits in the stratigraphic record. Though Chinese scientists have made great progress in this field, there are still many problems to be resolved, such as the identification of internal-wave and internal-tide deposits, the difference between these and other deep-water sediment types, the sedimentary mechanisms and formation conditions of internal-wave and internal-tide deposits and the relationship between the internal-wave and internal-tide deposits and the paleo-ocean and paleo-climate and so on. The most important reason for the present situation is that the research samples are too scarce. So we must 
strengthen the research to find more samples, and promote the development of this new research.

\section{Characteristics of internal-wave and internal-tide deposits}

Internal-wave and internal-tide deposits are well developed in diverse deep-water ocean environments. They have specific directed structure: bidirectional crosslaminations or cross-beddings ( He et al,1999; Wang et al, 2005). And flaser, wavy and lenticular beddings are usually observed. And they have characteristic sedimentary succession, the grain-size is rather fine and the bioturbate structures are scarce. Internal-wave and internal-tide deposits usually occur during the period of sea-level rise (He and Gao, 1999). In different environments and hydrodynamic conditions, their sedimentary characteristics and formation mechanism are different. Based on the documented research, we had summarized four kinds of sedimentary successions, five types of microfacies and three sedimentary models that were respectively formed in different sedimentary environments or conditions.

\subsection{Vertical sedimentary successions of inter-wave and internal-tide deposits}

The documented internal-wave and internal-tide deposits have four basic types of sedimentary sequence: (1) Bidirectional graded succession; (2) Unidirectional graded succession; (3) Bidirectional graded couplet succession; (4) Mudstone-oolitic limestone-mudstone succession (Fig. 2) (Gao et al, 1998; 2000; He et al, 1998; 2003).

Bidirectional graded succession (1). The fundamental feature of this succession is that the grain-size is coarsest in the middle and decreases upwards and downwards, which records the periodical changes of waning to waxing and again to waning hydrodynamic conditions. This succession consists mainly of sand-size sediment. Two subtypes of this succession can be identified according to the types of sedimentary structures (Fig. 2a, b).

Unidirectional graded succession (2). The feature of this succession is that the grain-size is coarsest in the lower part and gradually fines upwards. The basal contact with the underlying mudstone is sharp, but the contact with overlying muddy deposits is transitional. The two boundaries are quite different. This succession consists mainly of sandsize sediment. Two subtypes of this succession can also be identified according to the types of sedimentary structures (Fig. 2c, d).

Bidirectional graded couplet succession (3). This succession consists of a couplet of sandstone and mudstone. The ratio of sandstone to mudstone appears rhythmically in the vertical profile. (He et al, 1998; Guo et al, 2004)(Fig. 2e).

Mudstone-oolitic limestone-mudstone succession (4). This succession mainly developed in the clastic formation in the Middle and Upper Ordovician in the central Tarim Basin. And this succession consists of oolitic limestone or sandy oolitic limestone and mudstone. The contact of the oolitic limestone and the underlying and overlying mudstone is direct, mostly sharp. Sometimes the top contact is transitional (Gao et al, 2000; He et al, 2003) (Fig. 2f).

\subsection{Sedimentary microfacies types of inter-wave and internal-tide deposits}

The sedimentary microfacies types of the identified internal-wave and internal-tide deposits are summarized, such as bidirectional cross-lamination sandstone microfacies, unidirectional cross-bedding and cross-lamination sandstone microfacies, rhythmic alternating thin sandstone and mudstone microfacies, oolitic limestone or sandy oolitic limestone microfacies, flaser, wavy and lenticular bedded foraminiferal limestone microfacies and so on.

Bidirectional cross-lamination sandstone microfacies are well developed in the Ordovician of the Fincastle area, Appalachians, USA. These are characterized by welldeveloped bi-directional cross-lamination (up- and downchannel dipping) and are composed mainly of very finegrained lithic quartz graywacke and local siltstones (Gao and Eriksson, 1991). Interbedded with this microfacies are dark shale and thin turbidite beds. The sorting of this microfacies is clearly better than the turbidites. It displays bidirectional or unidirectional graded successions. This microfacies should be the deposits of alternating up- and down-channel currents caused by the internal tides. The high-frequency alternation of cross-lamination probably reflects the change of the influence of diurnal or semidiurnal tides. The grain-size changes from fine to coarse to fine in vertical profile record the changes of the maximal velocities and probably reflect the periodical changes of Neap to Spring to Neap tides.

Unidirectional cross-bedding and cross-lamination sandstone microfacies were observed in the Middle Ordovician of Fincastle area, the clastic formation in the Middle-Upper Ordovician in the central Tarim Basin and the Mesoproterozoic in Xiushui, Jiangxi (Gao and Eriksson, 1991; Gao et al, 2000; 2004; He et al, 2003;). This microfacies is characterized by the tabular cross-bedding and cross-laminations dipping channel and it is composed of medium- to fine-grain lithic graywacke. It also displays bidirectional graded succession. The features of paleocurrent direction indicate that this microfacies resulted from currents directed up the channel axis. It is probably resulted from unidirectional-dominated up -channel currents formed by the superimposition of an internal tide and a long period internal wave.

Rhythmic alternating thin sandstone and mudstone microfacies were found in all the documented internal-wave and internal-tide deposits in China (He et al, 1998; Gao et al, 2000; 2003; 2005; Jin et al, 2002; Guo et al, 2004). They are characterized by frequently alternating beds, consisting of thin sandstone and thin mudstone. This microfacies consists of couplets of gray fine-grained to very fine-grained sandstone, graywacke and dark gray mudstone. These thin alternating beds of sandstone and mudstone display rhythmic changes in the vertical profile, i.e. the sandstone-rich intervals and mudstone-rich intervals occur alternately and transition continuously and form wavy, lenticular, and flaser bedding. These features indicate that frequent alternation of bed load 


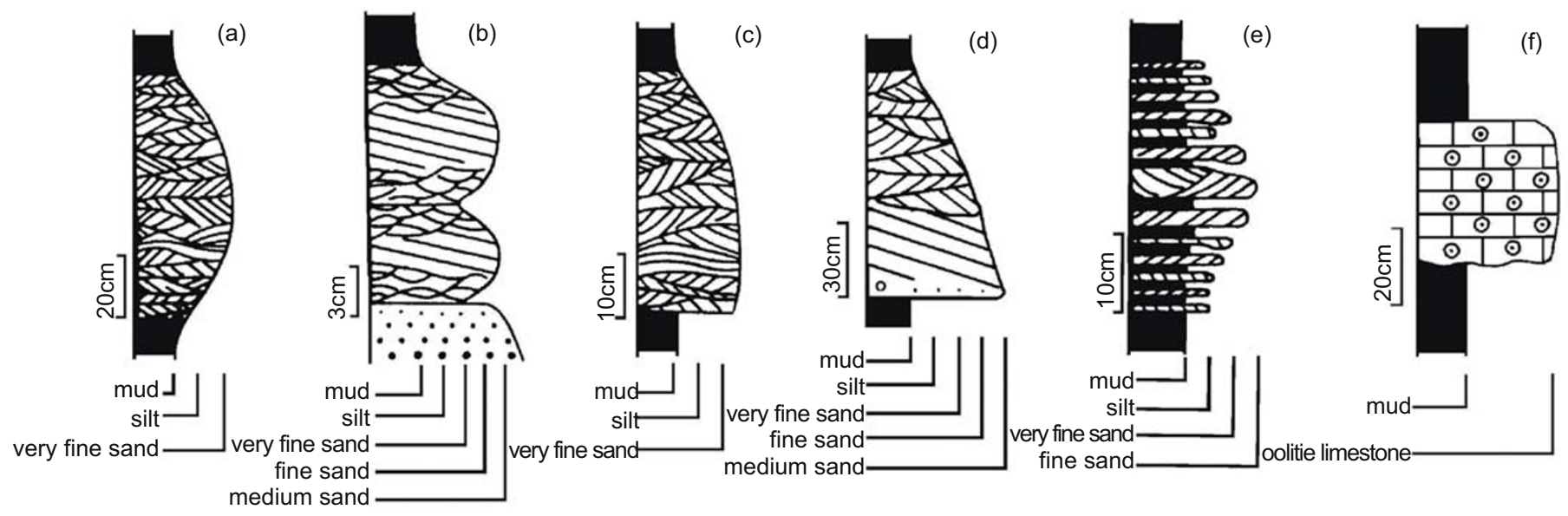

Fig. 2 Vertical successions of internal-tide and internal-wave deposits. ( synthesized from Gao et al, 1998; 2000; He et al, 1998; 2003 ) (a) bidirectional graded succession consisting of cross-lamination, (b) bidirectional graded succession consisting of medium-scale cross-bedding and small-scale laminations, (c) unidirectional graded succession consisting of cross-lamination, (d) unidirectional graded succession consisting of medium cross-beddings and bidirectional cross-laminations, (e) bidirectional graded couplet succession consisting of couplets of sandstone and mudstone, (f) mudstone-oolitic

limestone-mudstone succession

and suspension load deposition. This featured microfacies formed in deep-water slope environments, and is probably the product of internal tide deposition. This assemblage of sedimentary structures is also characteristic of tidal flats. However, the non-channelized, deep-sea environment is reducing and thus the color of sediments is different from those on tide flats, and indicators of exposure such as mudcracks are lacking.

Oolitic limestone or sandy oolitic limestone microfacies is developed in the Middle-Upper Ordovician in the Tarim basin within a thick succession of deep-water dark gray graptolitebearing shale. It is characterized by thin alternating beds of sandy oolitic limestone and dark-gray shale. The single layer of sandy oolitic limestone is usually $5-15 \mathrm{~cm}$, in which epsilon cross bedding is usually developed. Sandy oolitic limestone and dark-gray shale usually form thin alternating beds and display typical flaser, wavy and lenticular bedding, in which mainly sandy oolitic limestone has bidirectional cross laminations. This microfacies should be the result of internal tide deposition on the flat, deep-water slope. Epsilon cross bedding probably resulted from the lateral migration of small scale channels on the slope.

Flaser, wavy and lenticular bedded foraminiferal limestone microfacies is preserved in the Quaternary to Cretaceous cores from water depths of $2200 \mathrm{~m}$ to $3000 \mathrm{~m}$ on the Ontong-java Pleatau (Klein, 1975). It is mainly composed of foraminiferarich and coccolith-rich limestone with interbedded alternation volcaniclastic rocks, glauconitic siltstone and zeolitic clay beds. Contacts between the lithologies are transitional. Flaser, wavy and lenticular beddings are well developed in limestone and zeolitic clay beds. The thickness of the signal layer of this microfacies varies from a few centimeters to tens of centimeters thick.

Moreover, there are other types of microfacies, such as herringbone cross lamination siltstone microfacies, bundlelens-superimposed cross lamination siltstone microfacies, complicatedly interlaced cross lamination siltstone microfacies, thin alternate beds of sandstone and slate microfacies, flaser, wavy and lenticular bedding fine-grained sandstone, siltstone and slate microfacies (Jin et al, 2002; Guo et al, 2004). The features of these microfacies are partly similar to the five types of microfacies above. So they are not included in this paper.

\subsection{Sedimentary models of internal-wave and internal-tide deposits}

Three types of sedimentary models of internal-wave and internal-tide deposits are established. There are the sedimentary model in submarine channels, the sedimentary model in unchannelized continental slope environment and the sedimentary model on plateau.

In the slope environments where the submarine channels are well developed, and are characterized by the welldeveloped coarse debris gravity flow sediments during a lowstand of sea level, and the energy of internal waves and internal tides is not strong enough to rework the sand- and gravel-size terrigenous detritus introduced by gravity flows. It is difficult to form internal-wave and internal-tide deposits that can be identified easily. With a rise in sea level, the sedimentary area was far away from the source region, and the supply of the coarse debris was limited. Then internal tides and internal waves were capable of reworking the finegrained gravity flow sediments. In this kind of environment, the dominant microfacies are the first and the second type described above.

In unchannelized continental slope environments, internal tide currents have lower velocities than in the submarine channels. Under these conditions, thin interbeds of sandstone and mudstone were developed in response to alternating bed load and suspension load deposition. The deposits in this environment are dominated by microfacies 3 and 4 described above. The internal-tide deposits of the Upper Ordovician in Tonglu, Zhejiang and the Middle-Upper Ordovician in the Tarim basin conform to this model. 
Broad plateaux at abyssal and bathyal depths are also an advantageous location for the development of internaltide deposits. The topography of plateau is flat and the resistance to flow is small. Thus internal tidal currents can maintain critical velocities over a long distance, can transport fine-grained sediment and can form internal-tide deposits. Because the terrigenous detritus is scarce on the plateaux, so the internal-tide deposits mainly are the product of reworking of pelagic carbonate, the fifth type of microfacies described above is the dominant deposit of this environment.

\section{Characteristics and causes of large-scale sediment waves}

A noticeable discovery of deep-ocean investigations is that there are widely developed large-scale sediment waves at water depth of $2000 \mathrm{~m}$ to $4500 \mathrm{~m}$ in all oceanic basins, including sand waves and mud waves, especially mud waves (Faugeres et al, 1993; Howe, 1996; Marani et al, 1993; Normark et al, 1980; Richards et al, 1987; Roberts and Kidd, 1979). Normark et al (1980) summarized the characteristics of large-scale sediment waves in 30 documented areas, where large-scale sediment waves were well developed (Marani et al, 1993). Their wave-length varies from $0.3 \mathrm{~km}$ to $20 \mathrm{~km}$, mostly $1-10 \mathrm{~km}$; their wave-height varies from $1 \mathrm{~m}$ to 140 $\mathrm{m}$, mostly $10-100 \mathrm{~m}$. The slope degree of producing area is usually small, almost smaller than $0.3^{\circ}$, and the largest is not more than $1^{\circ}$. The interior structures of some large-scale sediment waves appear approximate sinusoidal curves (Fig. 3) (Howe, 1996), and some appear climbing imbricate structure (Richards et al, 1987). Most of these sediment waves migrate up the slope, a few migrate down the slope, still others do not migrate laterally and their shape is symmetrical. The sediments of sediment waves mainly consist of mud, and sometimes consist of sandy sediments.

There used to be three kinds of interpretations concerning the cause of large-scale sediment waves: 1) The result of turbidity currents, 2) The result of contour currents or reworking by bottom currents, 3) The result of slump. Later the possibility of internal waves was taken into consideration.

According to the re-examination of the data of large-scale sediment waves in modern deep-ocean, features such as wave shape, interior structure and migration direction can present convincing evidence of the cause. Most of these large-scale sediment waves are asymmetrical, but some of them are symmetrical. As well, their migration direction reflected by the interior structures is not only up the slope but also down the slope (Marani et al, 1993). Thus the gravity flows can not interpret this kind of phenomenon that can be completely explained by internal waves because internal waves propagate not only up the slope but also down the slope. However internal standing waves can form symmetrical large-scale sediment waves that do not migrate (Zhang et al, 2002). The direction of large-scale sediment waves shows they are not formed by contour currents, because the direction of these large-scale sediment waves ridge is always parallel to the strike of the slope and their migration direction is perpendicular to the direction of contour currents. At the same time, the shapes and interior structures of large-scale sediment waves also exclude the possibility that they are formed by slumping. The examples are the formation of deepwater sediment waves in the North-eastern Rockall Trough, North Atlantic Ocean (Zhang et al, 1999), the formation of large mud-waves on the levees of Toyama deep-sea channel in the Sea of Japan (Wang et al, 2004).

The new view on the cause of large-scale sediment waves

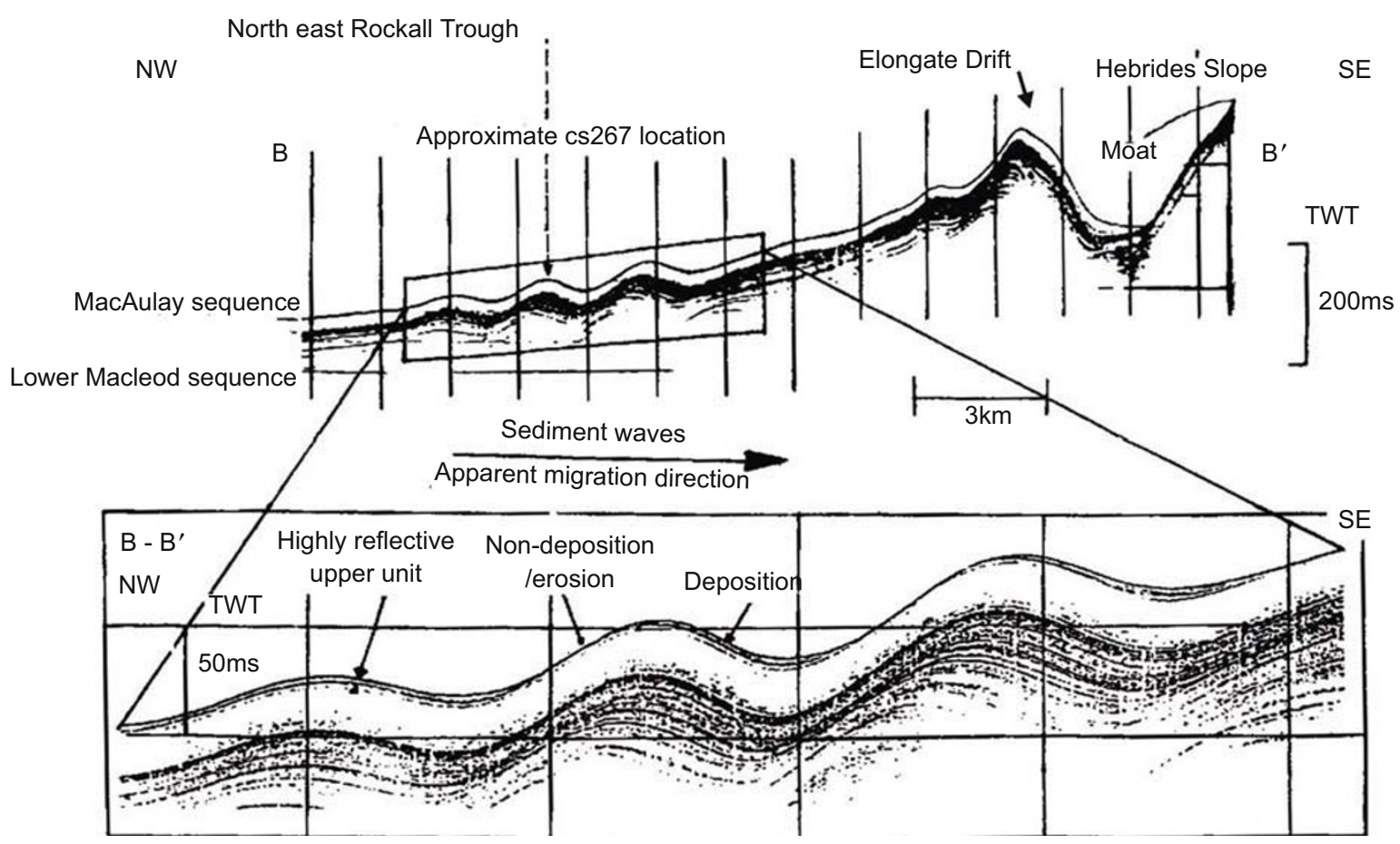

Fig. 3 High-resolution seismic reflection profile from the sediment waves of small area in northeastern Rockall Trough (after Howe, 1996) 
in modern deep-ocean is an important advance in the research field of internal-wave and internal-tide deposits. Now this new view has been applied to the recognition and research of the ancient large-scale sediment waves. And the first largescale sediment waves deposit in the stratigraphic record has been identified in the Middle and Upper Ordovician in center Tarim basin (Gao et al, 2000). This appears as a mound seismic unusual unit in the seismic profile. To the southwest of the unusual unit appears horizontal-trough strong amplitude seismic facies; to the north appears southwards dipping interrupted medium amplitude seismic facies; to the northwest appears obvious imbricate climbing weak-medium amplitude seismic facies, the seismic reflection events dip southwards, namely dip up the slope (Fig. 4). This feature absolutely conforms to the climbing large-scale sediment waves on Messina oceanic rise in the Mediterranean.

\section{Petroleum geology significance}

Internal-tide and internal-wave deposits are a new sedimentary type that has not been recognized until the last decade. This research will have important theoretical significance in developing the theory of sedimentology, and enriching the content of sedimentary facies and sedimentary environment. This research will also have important significance in the study of paleogeography, paleoenvironment, paleoclimate and paleogeotectonics and relevant subjects. Moreover, this research has important practical significance for sedimentary mineral resources, especially for petroleum exploration, because internal-tide deposits can form good reservoir bodies.
Similarly to turbidite and contourite, the interbeds of sandy internal-wave and internal-tide deposits and deep-water clay shale have favorable conditions of source-reservoir-cap rock. Moreover, these sediments are continuously washed by the deep-water tides and waves, so their textural maturity is much better than turbidite, and their primary and secondary porosity are well developed, their reservoir behavior is much better than turbidite. Furthermore, internal-wave and internaltide deposits can also form large-scale sedimentary bodies, for example large-scale sediment waves, especially sandy waves. Therefore, internal-wave and internal-tide deposits should be favorable exploration targets and potential reservoirs in deep-water deposits. Deep-water traction current deposit reservoirs provide a new frontier for oil and gas exploration in China. Geological and geophysical research indicates that the No.3 unusual seismic unit in the central Tarim Basin is a sedimentary sand body that has obvious features of a largescale sediment waves. In the Middle-Upper Ordovician clastic formation in this area, the reservoir bed quality is one of the best. The surrounding rock is formed from bathyal muddy deposits. The layer thickness and stacking thickness of these muddy deposits are both rather large, which have favorable seal capability. The muddy deposits are favorable for forming considerable size lithologic traps. This sedimentary sand body is near to the No. 1 fault in the central Tarim Basin, so the oil and gas produced by high quality source rock in overlying Middle Ordovician and Cambrian - Lower Ordovician could continuously migrate upwards via the No.1 fault and its derived secondary faults and fractures. Therefore the unusual unit that has the characteristics of a large-scale sediment wave has favorable hydrocarbon accumulation conditions. In addition, in the internal-wave and internal-tide
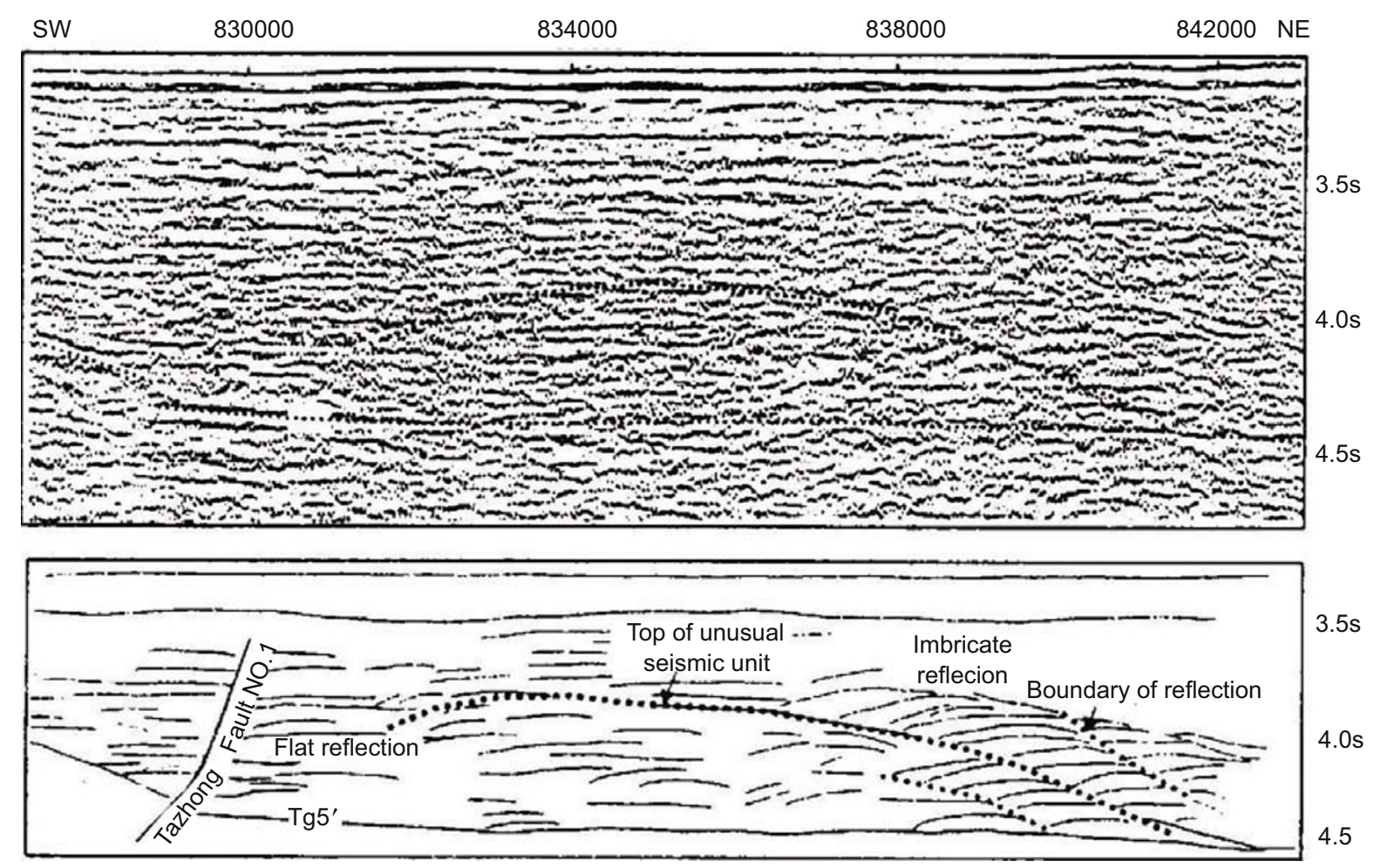

Fig. 4 Seismic profile (upper) and its geological explanation profile (lower) of No.3 unusual seismic unit in the central Tarim Basin 
deposits drilled in the central Tarim Basin, there are good oil and gas shows (Gao et al, 2000), in 17 layers, 5 wells, and the stacking length of the obtained cores that have different graded shows is 64.3 meters. All these features indicate the actual possibility of hydrocarbon accumulation.

There are multi-age marine deep-water deposits in most area of China, with good prospects for petroleum exploration in internal-wave and internal-tide deposits. As to the strata, they can be developed in Sinian to Ordovician, Devonian to Triassic and Jurassic in Tibet; As to the region, they can be developed in the northwest, southwest, center south, east of China. However, this new field has not been recognized fully as yet, let alone given enough attention by petroleum geologists. Therefore deep-water traction current deposits should be a focus of petroleum exploration in China. Before the exploration of internal-wave and internal-tide deposits, preparation should be emphasized, especially basic research. As far as the present situation is concerned, the Tarim Basin, the southern margin of the Yangtze Platform and the western margin of the Ordos Basin are the recommended areas.

\section{Acknowledgements}

This paper was supported by the National Natural Science Foundation (No. 40672071), the Teaching and Research Award Program for Outstanding Young Teachers in Higher Education Institutions of MOE, P.R.C., CNPC Innovation Foundation (2002F70102) and the program of Technological Innovation Team of Excellent Middle-aged and Youth Teachers in College of Hubei Province (T200602).

\section{References}

Du T, Wu W and Fang X H. The generation and distribution of ocean internal waves. Marine Science. 2001. 25(4): 25-28 (in Chinese)

Faugeres J C, Mwzerais M L and Stow D A V. Contourite drift types and their distribution in the North and South Atlantic Ocean basins. Sedimentary Geology. 1993. 82(1): 189-205

Gao Z Z and Eriksson K A. Internal-tide deposits in an Ordovician submarine channel: previously unrecognized facies? Geology. 1991. 19(7): 734-737

Gao Z Z and Eriksson K A. Internal-tide deposits in an Ordovician submarine channel, Fincastle, Appalachian, USA. Acta Sedimentologica Sinica. 1993. 11(1): 12-22 (in Chinese)

Gao Z Z, He Y B, Li J M, et al. The first internal-tide deposits found in China. Chinese Science Bulletin. 1997. 42(13): 1113-1116

Gao Z Z, He Y B, Luo S S, et al. Deep-Water Tractive Current Deposits - The Study of Internal-tide, Internal-wave, and Contour Currents. Beijing: Science Press. 1996. 1-46 (in Chinese )

Gao Z Z, Eriksson K A, He Y B, et al. Deep-Water Traction Current Deposits - A Study of Internal Tides, Internal waves, Contour Currents and Their Deposits. Science Press, Beijing \& New York, VSP Utrecht \& Tokyo. 1998. 1-56

Gao Z Z, He Y B, Zhang X Y, et al. Internal-wave and internal-tide deposits in the Middle-Upper Ordovician in the center Tarim basin. Acta Sedimentological Sinica. 2000. 18(3): 400-407 (in Chinese)

Gao Z Z, He Y B, Liu C X, et al. History, status and prospect of study on deep-water traction current deposits. Journal of Palaeogeography. 2006. 8(3): 331-338 (in Chinese)

Guo J Q, Zhang X H, Zhang Z J, et al. First discovery of internal-wave and internal-tide deposits from the Pre-Cambrian in northwestern Jiangxi. Chinese Journal of Geology. 2004. 39(3): 329-338 (in
Chinese)

He Y B and Gao Z Z. The characteristics and recognition of internal-tide and internal-wave deposits. Chinese Science Bulletin. 1999. 44(7): 582-589

He Y B, Gao Z Z, Guo C X, et al. Study on internal-wave and internaltide deposits of the third member of the Lower Cambrian Balang Formation at Yangjiaping, Shimen. Geology in China. 2005. 32(1): 62-69 (in Chinese)

He Y B, Gao Z Z, Li J M, et al. Internal-tide deposits of the late Ordovician in Tonglu, Zhejiang. Acta Sedimentological Sinica. 1998. 16(1): 1-7 (in Chinese)

He Y B, Gao Z Z, Zhang X Y, et al. Internal-tide deposits of the Middle-Upper Ordovician in well 32, Tarim basin. Journal of Palaeogeography. 2003. 5(4): 414-425 (in Chinese)

Howe J A. Turbidite and contourite sediment waves in the northern Rockall Trough, North Atlantic Ocean. Sedimentology. 1996. 43: 219-234

Jin H J, Li Y C and Fang G Q. Internal-wave and internal-tide deposits in the paleostratigraphic record of the western Qingling Mountains and their origins(in Chinese with English abstract ). Acta Sedimentological Sinica. 2002. 20(1): 80-84

Karl H A, Cacchione D A and Carlson P R. Internal-wave currents as a mechanism to account for large sand waves in Navarinsky Canyon head, Bering Sea. Journal of Sedimentary Petrology. 1986. 56(5): 706-714

Katsumata $\mathrm{K}$ and Hibiya $\mathrm{T}$. Internal wave generation by tidal flow over a sill in a rotating channel. Journal of Geophysical Research, C, Oceans. 2002. 107(10): 7-40

Klein G D. Resedimented pelagic carbonate and volcaniclastic sediments and sedimentary structures in Leg 30 DSDP cores from the Western Equatorial Pacific. Geology. 1975. 3: 39-42

LaFond E C. Internal waves. In: The Encyclopedia of Oceanography (Fairbridge R W ed.). NewYork: Reinhold, 1966. 402-408

Laird M G. Sedimentology of the Greenland Group in the Paparoa Range, west coast, South Island. N. Z. Journal of Geology and Geophysics. 1972. 15(3): 372-393

Lerczak J A, Winant C D and Hendershott M C. Observations of the semidiurnal internal tide on the southern California slope and shelf, Journal of Geophysical Research, C, Oceans. 2003. 108(3): 1-13

Marani M, Argnani A, Roveri M, et al. Sediment drifts and erosional surfaces in the central Mediterranean: seismic evidence of bottomcurrent activity. Sedimentary Geology. 1993. 82(1): 207-220

Mullins H T, Keller G H, Kofond J W, et al. Geology of Great Abaco Submarine Canyon (Blake Plateau): Observations from the research submersible "ALVIN". Marine Geology. 1982. 48: 239-257

Munk W. (1981) Internal waves and small-scale processes. In: Evolution of Physical Oceanography (Warren B A, Wunsch C. eds), 164-291. Massachusetts Institute of Technology, Cambridge.

Normark W R, Hess G R, Stow D A V, et al. Sediment waves on the Monterey fan levee: a preliminary physical interpretation. Marine Geology. 1980. 37: 1-18

Richards P C, Ritchie J D, Thompson A R. Evolution of deep water climbing dunes in the Rockall Trough -implication for overflow currents across the Wyville-Thompson Ridge in the Late Miocene. Marine Geology. 1987. 76: 177-183

Roberts D G and Kidd R B. Abyssal sediment wave fields on Feni Ridge, Rockall Trough: Long-range sonar studies. Marine Geology. 1979. 33: 175-191

Shepard F P. Tidal components of currents in submarine canyons. Journal of Geology. 1976. 84: 343-350

Shepard F P, Marshall N F, McLoughlin P A, et al. Currents in submarine canyons and other seavalleys. AAPG Studies in Geology. 1979. 8: 1-13

Wang Q C, Bao Z D and He P. The generation mechanism of orientating 
sedimentary structure by internal waves. Acta Sedimentological Sinica. 2005. 23(2): 255-259 (in Chinese)

Wang Q C, He Y B, He P, et al. The formation of large mud-waves on the levees of Toyama deep-sea channel in the Sea of Japan. Acta Oceanological Sinica. 2004. 26(6): 143-148

Yang D R. Oceanography. Beijing: High Education Press. 1986. 215-217 (in Chinese)

Yang S Z. New advance of internal waves in China. Marine Information. 1994. 9(6): 3-4 (in Chinese)
Zhang X Y, Gao Z Z and Yao X G. Internal-wave deposits in the Northeastern Rockall Trough, North Atlantic Ocean-reinterpretation of deep-water sediment waves formation. Acta Sedimentological Sinica. 1999. 17(3): 464-472 (in Chinese)

Zhang X Y, He Y B, Luo S S, et al. Deep-water sediment waves formed by internal waves. Journal of Palaeogeography. 2002, 4(2): 83-89 (in Chinese)

(Edited by Yang Lei) 